\title{
Conducta frente a filtraciones post gastrectomía vertical*
}

\author{
Drs. ATTILA CSENDES J. ${ }^{1}$, ITALO BRAGHETTO M. ${ }^{1}$, ANA MARÍA BURGOS L. ${ }^{1}$, \\ TAMARA PALAVECINO B. ${ }^{2}$, RODRIGO IGLESIAS F. ${ }^{2}$, CARMEN TORRIJOS C. ${ }^{2}$ \\ Departamento de Cirugía. \\ 2 Departamento de Radiología \\ Hospital Clínico Universidad de Chile. \\ Santiago, Chile.
}

\begin{abstract}
Manifestations and management of leaks after sleeve gastrectomy

Background: Sleeve gastrectomy is one of the most commonly used bariatric surgical procedures. Aim: To analyze clinical and laboratory manifestations and management of leaks after sleeve gastrectomy. Material and Methods: Analysis of 20 patients with leaks out of 785 operated subjects (2.5\%). Symptoms and laboratory changes were analyzed. Leak was classified according to the postoperative day of appearance, its location and its severity. Results: Fever, abdominal pain and tachycardia were the main clinical manifestations of the leak. Patients also had leukocytosis and an elevated C reactive protein. In $12(60 \%)$ patients, the leak appeared within the first four postoperative days, in three, it appeared between the fifth and ninth postoperative day and in five, after the tenth postoperative day. In $90 \%$, the leak was near the cardias. Eleven patients were reoperated and nine were managed conservatively. The leak closed 34 and 55 days after its appearance among patients managed conservatively or surgically, respectively. Conclusions: Leaks are a serious complication of sleeve gastrectomy and require a close surveillance of patients.
\end{abstract}

Key words: Sleeve gastrectomy, leak, obesity.

\section{Resumen}

Introducción: La gastrectomía vertical laparoscópica es una de las técnicas quirúrgicas más empleadas en pacientes con obesidad. El Objetivo de este trabajo es analizar los hallazgos clínicos y de laboratorio en pacientes con filtraciones post gastrectomía vertical, así como el tratamiento y la evolución clínica. Material y Método: El grupo estudiado comprende a 20 pacientes $(2,5 \%)$ de un total de 785 operados. En todos se evaluó la presencia de síntomas y signos clínicos, así como el hemograma y PCR. La filtración se clasificó de acuerdo a 3 parámetros: a) día de aparición de la filtración; b) su localización; c) su gravedad. Resultados: La presencia de fiebre, dolor abdominal y taquicardia fueron los principales síntomas y signos. Leucocitosis con desviación a izquierda y PCR elevados fueron hallazgos importantes. Hubo 12 pacientes $(60 \%)$ con filtra-

*Recibido el 26 de diciembre de 2012 y aceptado para publicación el 21 de enero de 2013.

Los autores no refieren conflictos de interés.

Correspondencia: Dr. Attila Csendes J.

Santos Dumont 999, Santiago, Chile. acsendes@redclinicauchile.cl 
ción precoz, 3 pacientes (15\%) con filtración de tipo intermedia y 5 pacientes $(25 \%)$ con filtración tardía. El $90 \%$ era de localización alta. Se reoperaron 11 pacientes y se manejaron conservadoramente 9 . El cierre de la filtración ocurrió en promedio 34 días después de la operación con manejo conservador y a los 55 días con manejo quirúrgico. No hubo mortalidad. Prótesis expansible se empleó en 4 pacientes. Conclusión: La filtración posterior a una gastrectomía vertical es un evento grave, que requiere una observación clínica muy cercana del paciente.

Palabras clave: Gastrectomía vertical, cirugía de obesidad, filtraciones, complicaciones.

\section{Introducción}

La gastrectomía vertical laparoscópica se ha convertido en una de las técnicas quirúrgicas más empleadas en el manejo de pacientes con obesidad de diferente grado $^{1-7}$. Tiene algunas ventajas como ausencia de anastomosis y de brechas mesentéricas, además de permitir el acceso fácil de la endoscopia al tracto biliopancreático. Sin embargo, tiene 3 importantes efectos adversos en el período postoperatorio inmediato, hemorragia de la línea de suturas, estenosis meso gástrica y filtración a nivel de la línea de sección gástrica.

El objetivo del presente estudio prospectivo fue resumir los principales hallazgos clínicos y de laboratorio en pacientes que presentaron una filtración postoperatoria, así como el manejo conservador o quirúrgico que se realizó.

\section{Material y Método}

\section{Pacientes estudiados}

Este protocolo de seguimiento prospectivo comenzó en octubre del año 2005, cuando se realizó la primera gastrectomía vertical laparoscópica. Desde entonces se han realizado, hasta julio del año 2012, un total de 785 procedimientos de este tipo. De ellos, 20 pacientes $(2,5 \%)$ presentaron la complicación de filtración y constituyen el presente estudio.

\section{Técnica quirúrgica}

Los detalles de la operación laparoscópica han sido publicados en extenso en reportes previos ${ }^{6,7}$. En todos se realizó la prueba del azul de metileno intraoperatorio para probar la impermeabilidad de la suturas. Se colocó un drenaje en el 75\% de los casos.

\section{Evaluación clínica}

En todos los pacientes, se realizó un cuidadoso control de signos y síntomas normales o patológicos durante su hospitalización y en los controles clínicos posteriores. La presencia de dolor abdominal, fiebre $\left(\mathrm{T}^{\circ}\right.$ sobre $37,5^{\circ} \mathrm{C}$ ) taquicardia (sobre 100 latidos/ minuto), distensión, náuseas o vómitos se registraron con especial cuidado. También se realizaron pruebas de laboratorio consecutivos, en especial hemograma y PCR.

\section{Estudio radiológico}

En todos los pacientes, se realizó un control radiológico, ya sea con sulfato de Bario líquido o con contraste hidrosoluble entre el $2^{\circ}$ y $3^{\text {er }}$ día postoperatorio, evaluando al "momento 0 " 3 características: anatomía del tubo gástrico creado, presencia de filtraciones y vaciamiento gástrico con presencia o ausencia de estenosis.

Estos estudios fueron cuidadosamente revisados por 2 de los autores (T.P. y R. I.).

\section{Clasificación de las filtraciones}

Nosotros hemos propuesto una clasificación para las filtraciones post bypass gástrico ${ }^{8,9}$, basados en una antigua clasificación para filtraciones post gastrectomía total ${ }^{10}$. Estos parámetros fueron adaptados para pacientes con gastrectomía vertical ${ }^{11,12}$ y se consideran los siguientes:

\section{a. Tiempo de aparición de la filtración}

1. Precoz, entre $1^{\circ}$ y $4^{\circ}$ día.

2. Intermedio, entre $5^{\circ}$ y $9^{\circ}$ día.

3. Tardío, mayor a 10 días.

b. Localización de la filtración

1. Alta (yuxtacardial).

2. Baja (antral).

\section{c. Severidad de la filtración}

1. Tipo I: Colección aérea o hidroaérea menor a $100 \mathrm{ml}$, localizada alrededor o cercana a la sutura gástrica, sin diseminación a mediastino, pleura o abdomen y sin compromiso clínico severo de tipo séptico.

2. Tipo II: Colección aérea o hidroaérea mayor a $100 \mathrm{ml}$, localizada cercana a la sutura gástrica, con diseminación a mediastino, pleura o cavidad abdominal y con claros signos clínicos de sepsis severa.

\section{Resultados}

En la Tabla 1 se muestran las características clínicas de pacientes con filtraciones post gastrectomía vertical. Este grupo de pacientes es enteramente similar al grupo total de pacientes sometidos a esta 
técnica. En la Tabla 2 se muestran los principales síntomas, signos y exámenes de laboratorio. Se aprecia que la fiebre es el hecho más frecuente. Con respecto a los exámenes de laboratorio, la PCR muy elevada estuvo presente en el $100 \%$ de los pacientes.

La Tabla 3 detalla la clasificación de las filtraciones según momento de aparición de la filtración y su severidad, tanto en pacientes sometidos a tratamiento conservador o quirúrgico. Se aprecian 2 principales hallazgos: a) filtraciones precoces son todos de tipo II. b) filtraciones tardías son todos de tipo I.

En la Tabla 4 se muestra la localización de las filtraciones según el tratamiento médico o quirúrgico. Se aprecia por una parte que todas las filtraciones que se operaron eran altas, mientras que 2 de 9 pacientes $(22 \%)$ con manejo conservador eran de tipo bajas.

En la Tabla 5 se detallan los métodos de diagnóstico según el tiempo de aparición de la filtración. En los pacientes con filtración precoz, el estudio radiológico demostró la presencia de esta complicación en 7 pacientes, mientras que el escáner abdominal lo confirmó en 4 pacientes. Sólo en 1 paciente se empleó la prueba de azul de metileno que salió positiva de inmediato a través del drenaje abdominal. En pacientes con filtraciones intermedias, tanto el estudio radiológico como el escáner fueron los que confirmaron esta complicación. En pacientes con filtraciones tardías, en todos, el estudio radiológico había sido normal al $3^{\text {er }}$ día. El diagnóstico de esta complicación se realizó por el escáner abdominal como método de elección.

La Tabla 6 detalla los procedimientos que se emplearon en el tratamiento conservador de esta complicación. El régimen 0 y la colocación de sonda nasoyeyunal por vía endoscópica permite la alimentación enteral. Se emplearon antibióticos de amplio espectro (Ceftriaxona y Metronidazol) y la colección peri gástrica se drenó por radiología intervencional. El cierre definitivo se confirmó con un estudio radiológico baritado y ocurrió en promedio 34 días después de la intervención.

En la Tabla 7 se describen los procedimientos quirúrgicos realizados en cada paciente. Destaca el hecho que los 3 pacientes que se reoperaron al $2^{\circ}$ día y en quienes se realizó una re sutura y colocación de drenaje evolucionaron bien, sin filtración posterior. Sin embargo, en los restantes pacientes que se resuturaron al $3^{\text {er }}$ día o más, esta sutura se abrió nuevamente, por lo que se manejaron con los drenajes colocados en la operación. El cierre promedio de la filtración ocurrió a los 54 días.

Prótesis expansible se utilizó en 4 pacientes. Un paciente sometido a tratamiento conservador recibió una prótesis al $9^{\circ}$ día, que se desplazó y se reposicionó, durando 20 días. En tres pacientes re opera-
Tabla 1. Características clínicas de pacientes con filtraciones post gastrectomía vertical. $\mathbf{n}=\mathbf{2 0}$

\begin{tabular}{|ll|}
\hline Género & $\begin{array}{l}13 \text { mujeres } \\
7 \text { hombres }\end{array}$ \\
\hline Edad promedio & 39,9 años (rango 17-64) \\
IMC $\left(\mathrm{kg} / \mathrm{m}^{2}\right)$ & $<35=6$ \\
Preoperatorio & $35,1-39,9=8$ \\
& $>/=40=6$ \\
\hline
\end{tabular}

Tabla 2. Síntomas, signos y exámenes de laboratorio en pacientes con filtración post gastrectomía vertical. $\mathbf{n}=\mathbf{2 0}$

\begin{tabular}{|lcc|}
\hline Dolor epigástrico & $\begin{array}{c}14 \\
(70 \%)\end{array}$ \\
\hline Fiebre $>37,5^{\circ} \mathrm{C}$ & $\begin{array}{c}17 \\
(85 \%)\end{array}$ & $\begin{array}{c}38 \pm 0,7 \\
(37,6-40)\end{array}$ \\
Taquicardia $>100 / \mathrm{min}$ & 12 & $115 \pm 9$ \\
& $(60 \%)$ & $(100-138)$ \\
Leucocitosis $>10.000 / \mathrm{mm}^{3}$ & 16 & $15.775 \pm 3.100$ \\
Desviación a izquierda $>4 \%$ & $(80 \%)$ & \\
\hline PCR (mg/lt) & $(70 \%)$ & $10,4 \pm 5$ \\
& $\begin{array}{c}20 \\
(100 \%)\end{array}$ & $\begin{array}{c}268 \pm 107 \\
(\text { normal } 20)\end{array}$ \\
\hline
\end{tabular}

Tabla 3. Clasificación de las filtraciones post gastrectomía vertical, según tratamiento. $\mathbf{n}=\mathbf{2 0}$

\begin{tabular}{|c|c|c|c|c|}
\hline & \multicolumn{2}{|c|}{$\begin{array}{c}\text { Tratamiento } \\
\text { conservador } \\
n=9\end{array}$} & \multicolumn{2}{|c|}{$\begin{array}{c}\text { Tratamiento } \\
\text { quirúrgico } \\
n=11\end{array}$} \\
\hline & $\begin{array}{c}\text { Tipo } \\
\text { I }\end{array}$ & $\begin{array}{c}\text { Tipo } \\
\text { II }\end{array}$ & $\begin{array}{c}\text { Tipo } \\
\text { I }\end{array}$ & $\begin{array}{c}\text { Tipo } \\
\text { II }\end{array}$ \\
\hline 1. Precoz: $1-4$ días & 0 & 4 & 0 & 8 \\
\hline 2. Intermedio: 5-9 días & 0 & 1 & 1 & 1 \\
\hline 3. Tardía: >/ 10 días & 4 & 0 & 1 & 0 \\
\hline
\end{tabular}

Total Tipo $\mathrm{I}=6(30 \%)$.

Total Tipo II $=14(70 \%)$.

Tabla 4. Clasificación de las filtraciones post gastrectomía vertical según localización. $\mathbf{n}=\mathbf{2 0}$

\begin{tabular}{|lccc|}
\hline & $\begin{array}{c}\text { Tratamiento } \\
\text { conservador } \\
\mathbf{n}=\mathbf{9}\end{array}$ & $\begin{array}{c}\text { Tratamiento } \\
\text { quirúrgico } \\
\mathbf{n}=\mathbf{1 1}\end{array}$ & Total \\
\hline Altas & 7 & 11 & $18(90 \%)$ \\
Bajas & 2 & 0 & $2(10 \%)$ \\
\hline
\end{tabular}


Tabla 5. Diagnóstico de filtración post gastrectomía vertical

\begin{tabular}{|lcll|}
\hline Tipo filtración & $\begin{array}{c}\text { Momento diagnóstico } \\
\text { (Día postop) }\end{array}$ & n pacientes & Método \\
\hline 1. Precoz: $\mathrm{n}=12(60 \%)$ & $2^{\circ}$ & 3 & $\mathrm{Rx}=2 \quad$ Azul Metileno $=1$ \\
& $5^{\circ}$ & 6 & $\mathrm{Rx}=3 \quad$ Escáner $=3$ \\
2. Intermedios: $\mathrm{n}=3(15 \%)$ & $4^{\circ}$ & 3 & $\mathrm{Rx}=2 \quad$ Escáner $=1$ \\
& $6^{\circ}$ & 1 & $\mathrm{Rx}$ \\
\hline 3. Tardías: $\mathrm{n}=5(25 \%)$ & $7^{\circ}$ & 1 & $\mathrm{Rx}$ \\
& $9^{\circ}$ & 1 & Escáner \\
& 12 & 1 & $\mathrm{Rx}$ normal en todos al $3^{\text {er }}$ día \\
& 15 & 1 & Diagnóstico por escáner tardío \\
\hline
\end{tabular}

Tabla 6. Tratamiento conservador de filtraciones post gastrectomía vertical. $n=9$

1. Régimen $=0$

2. Colocación endoscópica sonda naso-yeyunal

3. Alimentación enteral y en ocasiones parenteral

4. Antibióticos de amplio espectro

5. Drenaje percutáneo (1 o varios por radiología intervencional)

6. Control con escáner cada 7 días

7. Control final con estudio radiológico del tubo digestivo. Cierre filtración 34,3 días (17-61)

Tabla 7. Tratamiento quirúrgico de las filtraciones post gastrectomía vertical. $n=11$

\begin{tabular}{|ccl|}
\hline Paciente & Día reop & Operación \\
\hline 1 & $2^{\circ}$ & Resutura $=$ bien \\
2 & $2^{\circ}$ & Resutura $=$ bien \\
\hline 3 & $2^{\circ}$ & Resutura $=$ bien \\
\hline 4 & $3^{\circ}$ & Resutura $=$ no sirvió \\
\hline 5 & $3^{\circ}$ & Resutura $=$ no sirvió \\
\hline 6 & $3^{\circ}$ & Resutura $=$ no sirvió \\
\hline 7 & $3^{\circ}$ & Aseo y drenaje \\
8 & $4^{\circ}$ & Resutura $=$ no sirvió \\
\hline 9 & $7^{\circ}$ & Aseo y drenaje \\
10 & $9^{\circ}$ & Aseo y drenaje \\
\hline 11 & $12^{\circ}$ & Aseo y drenaje \\
\hline
\end{tabular}

Cierre filtración $=53,5$ días $(8-120)$. dos también se colocó una prótesis: uno no toleró este procedimiento ya que se desplazó y se retiró. En otro paciente también se desplazó, se reposicionó y se mantuvo por 12 días. En un único paciente se logró mantener la prótesis sin complicaciones por 35 días. No hubo mortalidad en la presente serie.

\section{Discusión}

La aparición de una filtración de la línea de sutura después de una gastrectomía vertical en pacientes con obesidad, representa un efecto adverso muy complejo que afecta no sólo al paciente, sino al equipo quirúrgico y a la familia. Por lo tanto, dada sus características, es imposible realizar ningún estudio prospectivo y randomizado, ya que cada paciente representa un verdadero desafío. El propósito del presente estudio es mostrar el manejo global de estos pacientes y sugerir algunas conductas de tratamiento, pero que en ningún caso representan normas de tratamiento definitivo. Las cifras internacionales publicadas referentes a estas complicaciones oscilan entre $0,7 \%$ y $5,3 \%$, con un promedio de $2,5 \% \%^{6}$, que es muy similar a nuestro estudio: ¿Por qué se producen estas filtraciones? Por lo menos hay 3 posibilidades: a) posición incorrecta de la línea de corchetes a nivel del ángulo de His, con inclusión de la unión gastroesofágica; b) estenosis de la porción media de la gastrectomía, con hipertensión intraluminal ya sea por estenosis verdadera, torsión del estómago o acodadura a nivel de la incisura y c) Isquemia o quemadura del borde de sección gástrica, por los elementos de coagulación que se emplean. Nosotros pensamos que esta última opción es probablemente la más frecuente. 
El punto más crucial es el diagnóstico precoz y el tratamiento adecuado. Hemos aprendido que la evaluación de los pacientes varias veces al día puede detectar precozmente esta complicación, ya sea por aparición de fiebre o taquicardia. La realización de exámenes (Hemograma y PCR) ayuda enormemente al diagnóstico. En un estudio de la evolución de estos parámetros en pacientes sometidos a cirugía bariátrica por vía laparoscópica y con una evolución postoperatoria normal, se demostró que la PCR se eleva en promedio a valores de 50 el $3^{\text {er }}$ día y $5^{\circ}$ día postoperatorio ${ }^{13}$, cifras muy distantes de los valores de cerca de 250. Lo mismo ocurre con los leucocitos. En estas circunstancias, un escáner de abdomen y pelvis, seguidos de un estudio radiológico con Bario líquido o con contraste hidrosoluble, confirmarán o descartarán esta complicación. Planteamos que es útil determinar 3 parámetros si aparece una filtración postoperatoria, ya que podrían sugerir la necesidad de una reoperación o eventualmente sólo un tratamiento conservador:

a. Día de aparición postoperatoria.

b. Localización de la filtración.

c. Severidad clínica de la filtración.

Estos parámetros han sido útiles tanto en el tratamiento de las filtraciones post bypass gástrico ${ }^{8,9}$, como en el presente estudio. En general, pacientes con filtración precoz, antes del $4^{\circ}$ día y de localización alta, la terapia quirúrgica parece aconsejable. Por el contrario, filtraciones intermedias o tardías pueden manejarse conservadoramente, ya que pueden ser de tipo I y de la localización alta o baja: Nuestro estudio sugiere además que si la reoperación es precoz, al $2^{\circ}$ día postoperatorio, una resutura del sitio de la filtración o drenajes adecuados pueden evitar una filtración posterior. Por el contrario, si esta reoperación es posterior al $3^{\text {er }}$ día postoperatorio, la resutura está condenada al fracaso y sólo se debe realizar un buen aseo, drenajes adecuados y colocación de sonda nasoyeyunal, lo que puede resultar en una evolución favorable. El uso de drenajes en esta cirugía es controversial, al igual que en toda cirugía abdominal en el que hay acceso al lumen digestivo. En nuestros pacientes hemos empleado un drenaje en el $75 \%$ de los casos, probablemente por cumplir con un antiguo protocolo del uso obligatorio de drenajes. Sin embargo, un estudio reciente de Maluenda (no publicado aún) de 400 pacientes sometidos a este procedimiento recomienda el no uso de drenajes.

No hemos empleado nunca una yeyunostomía, que significa una sutura intestinal y un manejo más complejo desde el punto de vista nutricional y de enfermería. La sonda nasoyeyunal se puede reponer por vía endoscópica varias veces, e incluso se puede colocar una prótesis expansible que puede acelerar la cicatrización. Sin embargo, este abordaje tiene también serios efectos adversos como intolerancia del paciente o desplazamiento, lo que requiere de un control estricto.

El cierre definitivo de una filtración post gastrectomía vertical puede ser casi 20 días más largo que después de un bypass gástrico por al menos 2 factores: a) después de bypass gástrico, sólo hay un poco de saliva en la bolsa gástrica, ya que no hay ácido ni reflujo biliar. Por el contrario, después de gastrectomía vertical no sólo hay saliva en el estómago, sino secreción de ácido y reflujo de bilis a través del píloro. b) se ha descrito que con la creación de este tubo gástrico largo, la presión intraluminal es mayor ${ }^{13}$ lo que podría favorecer la mantención de la filtración.

¿Cómo prevenir esta complicación? Es obvio que los principios generales de, manejo suave de los tejidos, selección apropiada de la técnica, control de la hemorragia y evitar estenosis del tubo gástrico son principios generales de toda cirugía abdominal. El manejo cuidadoso del electrocauterio y de los sistemas de sello vascular nos parece imprescindible. La realización de pruebas intraoperatorias para comprobar la impermeabilidad de las suturas debe ser rutinario, aún cuando sabemos que esta maniobra no previene la aparición de una filtración, sino que demuestra que la técnica quirúrgica está adecuada en ese momento. El refuerzo de la línea de corchetes no ha demostrado capacidad de prevenir esta filtración, sino incluso puede aumentarlo por los orificios que hacen las agujas y una eventual isquemia.

En conclusión, la filtración post gastrectomía vertical es un evento serio, que requiere una cercana observación del paciente. Parece ser útil determinar 3 características de esta filtración con el objeto de proponer el mejor tratamiento en cada paciente en particular.

\section{Referencias}

1. Baltasar A, Serra C, Pérez N, Bou R, Bengochea M, Ferri L. Laparoscopic sleeve gastrectomy; a multi-purpose bariatric operation. Obes Surg. 2005;15:1124-8.

2. Baltasar A, Bou R, Bengochea M, Serra C, Pérez N. Mil operaciones bariátricas. Cir Esp. 2006;79:349-55.

3. Hamoui N, Anthone GJ, Kaufman HS, Crookes PF. Sleeve gastrectomy in the high-risk patient. Obes Surg. 2006;16:1445-9.

4. Roa PE, Kaidar-Person O, Pinto D, Cho M, Szomstein S, Rosenthal RJ. Laparoscopic sleeve gastrectomy as treatment for morbid obesity: technique and short-term outcome. Obes Surg. 2006;16:1323-6

5. Melissas J, Koukouraki S, Askoxylakis J, Stathaki M, Daskalakis M, Perisinakis K, et al. Sleeve gastrectomy-a 
restrictive procedure? Obes Surg. 2007;17:57-62.

6. Braghetto I, Korn O, Valladares H, Gutiérrez L, Csendes A, Debandi A, et al. Laparoscopic sleeve gastrectomy: surgical technique, indications and clinical results. Obes Surg. 2007; 17:1442-50.

7. Csendes A, Braghetto I. Sleeve gastrectomy. Surg. Today 2008;38:479.

8. Csendes A, Burdiles P, Burgos AM, Maluenda F, Diaz JC. Conservative management of anastomotic leaks after 557 open gastric bypasses. Obes Surg. 2005;15:1252-6.

9. Csendes A. Conservative management of anastomotic leaks. Obes. Surg. 2006;16:375-6.

10. Csendes A, Díaz JC, Burdiles P, Braghetto I, Maluenda F, Nava O, et al. Classification and treatment of anastomotic leakage after extended total gastrectomy in gastric carcinoma. Hepatogastroenterology 1990;37:174-7.
11. Burgos AM, Braghetto I, Csendes A, Maluenda F, Korn $\mathrm{O}$, Yarmuch J, et al. Gastric leak after laparoscopic sleeve gastrectomy for obesity. Obes. Surg. 2009;19:16721677.

12. Csendes A, Braghetto I, León P, Burgos AM. Management of leaks after laparoscopic sleeve gastrectomy in patients with obesity. J Gastrointest Surg. 2010;14:1343-8.

13.- Yehoshua RT, Eidelman LA, Stein M, Fichman S, Mazor A, Chen J, et al. Laparoscopic sleeve gastrectomy-Volume and pressure assessment. Obes Surg. 2008;18:1083-8.

14. Csendes A, Burgos AM, Roizblatt D, Garay C, Bezama $\mathrm{P}$. Inflammatory response measured by body temperature, C-reactive protein and white blood cell count 1,3 and 5 days after laparotómica or laparoscopic gastric bypass surgery. Obes Surg. 2009;19:890-3. 